\title{
RESENHA
}

PAVEAU, M. A. Os pré-discursos: sentido, memória, cognição. (trad. Greiciely costa e Débora Massman) Campinas: Pontes, 2013.ISBN: 978-85-7113-470-6.

\section{Por uma teoria dos pré-discursos}

\author{
For a theory of pre-speeches
}

\section{Raquel Tiemi Masuda Mareco André William Alves de Assis}

Universidade Estadual de Maringá - UEM - Maringá - Paraná - Brasil

Na obra "Os pré-discursos: sentido, memória, cognição", Marie-Anne Paveau, professora de linguística da Universidade de Paris 13, na França, apresenta uma proposta bastante instigante que consiste em acrescentar à análise do discurso uma dimensão cognitiva. Esse "encontro interdisciplinar" é justificado por "razões que mantêm tanto a evolução da análise do discurso quanto aquela das ciências da cognição" (p. 10). Paveau tem como objetivo elaborar uma descrição teóricoanalítica do que ela denomina "pré-discurso". Para isso, baseada em seu corpus e em um referencial teórico de fôlego, problematiza a questão das informações prévias ao discurso, principalmente o ponto de articulação entre os dados anteriores e as produções verbais.

O livro está dividido em sete capítulos. No primeiro, "Por que pré-discursos?", Paveau produziu uma descrição terminológica e conceitual dos termos "prédiscurso", "pré-discursivos", "pré-liguageiro" e "pré-linguístico", apresentando suas ocorrências e suas fontes no campo da linguística e em outros. Para a autora, esses e outros termos são costumeiramente dados como equivalentes para designar "os dados anteriores ao discurso que são mobilizados na sua produção" (p. 15). Paveau contesta essa definição, pois para ela não se trata de "discursos produzidos antes, mas sim das anterioridades do discurso" (p. 20); a autora parte de conceitos diversos para designar o que é "comum" nos discursos produzidos e interpretados e afirma que os dados coletivos são anteriores aos discursos, ao mesmo tempo em que são elaborados pelos discursos como efeito de evidência. Noções como doxa, coletivo, partilha e comum são mobilizadas pela autora por contribuírem com a conceituação de pré-discurso, por isso discorre sobre cada uma delas apresentando suas etimologias e diferentes sentidos em perspectivas diversas, problematizando também as noções de crença, preconceito, prejulgamento, representação e estereótipo. 
No capítulo seguinte, "Posições nas ciências da linguagem", Paveau resenha alguns textos que trazem um sentido anterior coletivo, embasados no funcionamento do discurso em relação aos dados anteriores e partilhados. Essa proposta é apresentada sob três perspectivas: a análise do discurso, a pragmática e a semântica. Sob a perspectiva da análise do discurso, a autora mobiliza os conceitos de pré-construído, interdiscurso e intradiscurso, demonstrando como eles se articulam e contribuem para sua reflexão sobre os pré-discursos. No campo da pragmática, discorre sobre concepções de senso comum, de sentido e de doxa para justificar sua preferência pelo termo prédiscurso, que pressupõe uma ancoragem em uma historicidade do sentido. Já no domínio da semântica, a autora opta por privilegiar "uma renovação da semântica cognitiva", apresentando brevemente algumas ideias de V. Nyckees (1999 apud PAVEAU, 2013), a quem atribui, como grande mérito, a inscrição da história na semântica. Nas palavras da autora, "colocar a história no centro de uma teoria da significação é colocar em primeiro plano as condições de constituição do sentido, o conjunto de experiências humanas" (p. 88).

"Memória no discurso" é o título do terceiro capítulo do livro. Logo no início, Paveau questiona se tudo na língua e no discurso não poderia ser denominado de memória, já que o termo não se deixa definir tão facilmente em linguística, nem circunscrever-se por pares como história/memória. A noção de intersubjetividade, abordada no capítulo 1, é retomada neste momento para promover uma reflexão sobre a memória coletiva. Para a autora, deve-se buscar uma forma de articular conceitualmente o individual e o coletivo. Nesse sentido, distingue três subsistemas para a memória: o registro sensorial, a memória a curto prazo e a memória a longo prazo. Esta última se divide em memória episódica e memória semântica de uma lado, e memória implícita e explícita do outro. Para a construção de uma teoria dos pré-discursos, que considere integralmente a noção de memória, Paveau absorve três pontos de todas as linhas e vertentes apresentadas: a) a preexistência de sequências discursivas; b) o papel da memória na referência nominal; e c) a identificação ou recuperação de antecessores, pelo viés da noção de "domínio de formulações-origens" (p. 101). A autora propõe que a análise do discurso deve levar em consideração categorias para se pensar uma memória não apenas discursiva ou interdiscursiva, mas uma memória discursivo-cognitiva e uma des-memória.

No quarto capítulo, "Para uma teoria dos pré-discursos", Marie-Anne Paveau nos apresenta sua conceituação de pré-discursos, sob a perspectiva da cognição distribuída. A autora define pré-discursos "como um conjunto de quadros prédiscursivos coletivos (saberes, crenças, práticas), que dão instruções para a produção e para a interpretação do sentido no discurso" (p. 130). A esses quadros, atribui seis propriedades específicas: 1) coletividade, uma vez que os quadros pré-discursivos coletivos são partilhados coletivamente (social), mas apropriados individualmente; 2) imaterialidade, pois os pré-discursos não se inscreverem na materialidade discursiva, contudo "imprimem nela mascas 
indiretas"; 3) transmissibilidade, que abrange o coletivo nos quadros prédiscursivos e se desdobra em eixos sincrônicos e diacrônicos; 4) experimentalidade, visto que os quadros pré-discursivos coletivos possibilitam a organização da experiência e permitem-se fazer previsões quanto aos discursos que podem ser produzidos; 5) intersubjetividade, relacionada à aproximação (não submissão ao critério de verdade lógica) e à relatividade (entendido como adaptáveis ao saberes e crenças coletivos); 6) discursividade, uma vez que os pré-discursos são linguisticamente analisáveis por se manifestarem no discurso. Dentro da proposta da autora, o cognitivo se diferencia da proposta cartesiana em que se considera apenas os esquemas mentais. Para Paveau, o cognitivo funciona como ferramentas de tecnologia discursiva, instrumentos, materiais ou não, que permitem "trabalhar e fabricar os pré-discursos, tendo em vista a elaboração dos discursos" (p. 146). O capítulo é encerrado com exemplos de corpora e metodologias para se analisar os pré-discursos.

Em "Filiações Discursivas", quinto capítulo do livro, a autora dá destaque aos "predecessores" dos pré-discursos. Para ela, os falantes de uma língua recorrem a dois dispositivos distintos e complementares na produção discursiva: a) uma "memória da língua", que se ancora em uma lei da língua: um "conjunto de lembranças que concerne ao sentido das palavras" (p. 160), como aqueles provenientes de dicionários, guias de francês correto; b) uma "memória discursiva patrimonial", ancorada em uma sabedoria coletiva. A memória da língua é observada no corpus de Paveau em relação ao etimologismo, que confere autoridade às palavras primitivas, como forma de argumento de bom uso e verdadeiro sentido da língua. Esse, por sua vez, pode ser observado em ocorrências de retorno à origem latina, a manipulação sobre o francês e a lembrança da existência da prova. Tais recursos etimológicos são como traços de uso cognitivo da linguagem. A memória da língua também é observada na análise de Paveau pelo uso das aspas, normalmente acompanhada pela rejeição discursiva; o comentário lexicológico espontâneo, em formulações de asserções críticas sobre empregos lexicais de campos diversos; e o lexicografismo, menções lexicográficas sem que se levante uma aparelhagem teórica, baseada em uma lexicografia popular. Em relação à memória discursiva patrimonial, a autora aborda o que denomina de "memória dos antigos", manifestações de apelos à sabedoria coletiva anônima, autoridade dos percursores. Paveau também aborda como memória dos antigos a noção de nome próprio, para ela um "nome de memória" por ser um fenômeno portador de sentido, o que lhe permite um olhar discursivo.

No sexto capítulo do livro, Marie-Anne Paveau aborda a noção de "Mundos partilhados" por considerar a partilha uma necessidade comunicacional. Para a autora, os locutores possuem objetivos mínimos do sentido e um imperativo cognitivo. Partindo do princípio de que os pré-discursos possuem propriedades observáveis como partilhas semânticas, manifestadas na língua, ela problematiza a noção de dêixis enciclopédica, propondo observá-la em suas duas 
manifestações: 1) dêixis enciclopédica marcada, ocorrências de referências que não são nem pessoa, nem espacial, nem temporal, nem textual, nem discursiva, mas constroem uma referência do tipo enciclopédico por meio de demonstrativos e da pessoa; 2) dêixis enciclopédica não marcada, ocorrências de formas lexicais ou sintáticas que não são habitualmente classificadas como dêiticos, entretanto convocam dados culturais e memoriais partilhados pelo grupo e pelos usuários da língua. Em relação à partilha, a autora aborda a questão das interrogações genéricas: frases interrogativas generalizantes que pressupõem uma verdade pré-discursiva. O uso de modalidades epistêmicas, como ancoragem nos prédiscursos, abre espaço para que Paveau aborde a noção de evidência, considerando-a como uma experiência construída no discurso, que se apresenta como exterior a ele. Essa experiência é utilizada pelos locutores como um prédiscurso que orienta os discursos em uma base epistêmica.

O último capítulo do livro é dedicado aos "Organizadores textual-cognitivos". Segundo a autora, esses organizadores situam-se em um meio caminho entre a elaboração mental e a construção textual. Na análise de seu corpus, Paveau listou três organizadores, os mais recorrentes, de percepção de mundo. São eles: 1) a tipologia, que abrange um processo de listagem num processo de organização e percepção do mundo e organiza tanto as representações do mundo, quanto os discursos que se produz; 2) a metáfora, organizador que agrupar diferentes níveis de organização: psíquico, cognitivo, discursivo e textual que constitui um saber (histórico, cultural) e, ao mesmo tempo, valida-o em diferentes asserções estáveis; 3) a antítese, categorizada em: a) formal, apresenta-se no discurso um mundo binário que provém de um apelo às formas de oposição, b) cultural, que se constrói por uma longa memória, revelando o horizonte memorial do discurso; c) histórica, retomando o exemplo bárbaro $\mathrm{x}$ civilizado, atribuindo-lhe $o$ estatuto de organizador psíquico semântico e discursivo no que se refere aos discursos sobre a escola. Enfim, esses três conceitos são, para Paveau, poderosos organizadores discursivos.

Após a apresentação desses sete capítulos, Paveau tece suas considerações finais em "Discurso e cognição: uma nova perspectiva em análise do discurso?". Nesse fechamento, ressalta que a sua proposta abre espaço para que a análise do discurso possa ser enriquecida com as contribuições de uma dimensão sóciocognitiva, na perspectiva da cognição distribuída. A autora alerta que "as mudanças de paradigma são necessárias ao processo científico e a análise do discurso não escapa à regra" (p. 242).

Desde o começo da obra, Marie-Anne Paveau tem deixado claro que não nega nem as raízes da análise do discurso nem as raízes das ciências da cognição. Em suas palavras: "não concebo teoria sem herança" (p. 12), nesse sentido propõe uma articulação entre essas disciplinas com o intuito de contribuir para o estudo de ambas, proporcionando-Ihes um novo olhar. "Os pré-discursos: sentido, memória, cognição" é uma obra densa que exige do leitor um conhecimento prévio aprofundado das teorias discursivas, além de outras teorias 
que a autora articula para justificar sua proposta no âmbito da cognição. Propor uma análise cognitiva do discurso é uma atitude ousada e, por muitos, inesperado. Por apresentar um percurso inovador, que propõe movimento para as teorias linguístico-discursivas, acreditamos que poderá sofrer críticas, principalmente por parte dos analistas do discurso ortodoxos. Em suma, trata-se de um material bastante denso que interessa a pesquisadores que têm como objeto o discurso, em suas diferentes perspectivas, e que estejam abertos para problematizar as noções discursivas levantadas pela autora em um âmbito filosófico-cognitivo-discursivo. 